\title{
Analysis of Childhood Obesity in Alabama and Delaware: A Cohort Study
}

\author{
Onyinye Maria Muomah \\ Masters of Public Health Epidemiology, Liberty University, Lynchburg, USA \\ Email:maria.muomah@gmail.com
}

How to cite this paper: Muomah, O.M. (2021) Analysis of Childhood Obesity in Alabama and Delaware: A Cohort Study. Open Journal of Pediatrics, 11, 570-579. https://doi.org/10.4236/ojped.2021.114053

Received: September 25, 2021

Accepted: October 25, 2021

Published: October 28, 2021

Copyright $\odot 2021$ by author(s) and Scientific Research Publishing Inc. This work is licensed under the Creative Commons Attribution International License (CC BY 4.0).

http://creativecommons.org/licenses/by/4.0/

\section{(c) (i) Open Access}

\begin{abstract}
Objective: The objective is to evaluate data sets for children aged 24 to 59 months that identified the risk factors of being obese and overweight and compare it between two U.S. states (Alabama and Delaware). Methods: An analysis of survey data sets published between 2013 and 2017, comparing the factors of obesity and its prevalence amongst different races of 50,760 children aged 24 to 59 months in the U.S., was conducted using Microsoft Excel 2016 and IBM SPSS version 1.0.0. Results: Hispanic children have the highest rate of obesity in the U.S compared to all other races. Children aged $2-4$ years old from Alabama were more at risk for being overweight and obese compared to those from Delaware. Those between the ages of 48 - 59 months of age were more at risk than the other age groups. Conclusions: Childhood obesity is a predisposing factor for adult obesity. There is a need to identify the risk factors of obesity early in a person's life and address them appropriately.
\end{abstract}

\section{Keywords}

Obesity, Overweight, Hispanics, Children, Body Mass Index, Analysis

\section{Background}

One of the health issues facing the world, more specifically the U.S., is obesity. This health issue is more prevalent in minority populations including non-Hispanic black and Hispanic children and adolescents than in their Caucasian counterparts [1]. Studies show that one in six U.S children and teens are obese [2]. Childhood obesity is also one of the major contributors to adult obesity. According to CDC, obesity is defined as an excess in body fat, with a BMI at or above the 95th percentile for children and teens of the same age and sex [3]. Some of the tools and techniques used to effectively measure body fat and BMI 
include underwater weighing (densitometry), multi-frequency bioelectrical impedance analysis (BIA), magnetic resonance imaging (MRI), waist circumference, and skin-fold thickness [4]. Worldwide, factors such as the environment that one grows up in, lifestyle preferences and culture play an important role in the rising prevalence of obesity [4].

One's diet habits play a huge role as well. A source mentions that a poorquality diet that consists of high-calorie foods lacking the necessary micronutrients needed for optimal neurobehavioral development and growth can contribute to the issue of obesity and cause severe diet-related chronic diseases and deficits in learning capacities [5]. If nothing is done about this health issue, the child is at risk for developing chronic diseases later in life. The hypothesis of this research is to examine the contributing factors to childhood obesity in Hispanic children in the U.S., compared to other populations. For children living in the United States, other contributing factors to obesity are family income level, parent's educational level, geographical location, and immigration status. To reduce the prevalence of childhood obesity, several evidence-based public health strategies have been put in place. This includes, promoting breastfeeding, limiting screen time, encouraging physical activity, increasing fruit and vegetable consumption, regulating portion size, and limiting the intake of sugar-sweetened beverages [6].

\section{Methods}

The dataset used for this study is titled, the Nutrition, Physical Activity, and Obesity-Women, Infant, and Child. It includes data on the weight status for young children aged 3 months to 4 years old from Women, Infant, and Children Participant and Program Characteristics (WIC-PC). WIC is a program put in place by the Food and Nutrition Service of the U.S. Department of Agriculture (USDA) to provide a combination of direct nutritional supplementation, nutrition education and counseling, and increased access to health care and social service providers for pregnant, breastfeeding, and postpartum women; infants; and children up to age five [7].

Data was collected between the time periods of 2008 to 2014 for all states in the U.S. To determine the child's weight status, questions such as percent of WIC children aged 2 to 4 years who have an overweight classification, percent of WIC children aged 2 to 4 years who have obesity, and percent of WIC children aged 3 - 23 months old who have a high weight-for-length was asked. Variables such as sample size, low and high confidence intervals, were all calculated.

An analysis of the survey data sets across the different states in the U.S. comparing the risk factors of being overweight and obese and its prevalence amongst different races of children aged 24 months to 59 months old in the U.S, was done using Microsoft Excel 2016. Birth dates were used to calculate age. Children were assigned to a weight status category of overweight (BMI $\geq 85^{\text {th }}$ percentile and $<95^{\text {th }}$ percentile) or obese ( $\geq 95^{\text {th }}$ percentile) based on CDC growth chart criteria. 
Analysis was done for two U.S. states with a higher prevalence of childhood obesity in Alabama and Delaware. Variables such as age, gender, and race were analyzed. A clustered column was then created to interpret the individual data sets and represent the figures. 50,760 children aged 24 months to 59 months in two different U.S states were a part of this study. For the states of Alabama and Delaware, the 2014 data was used. Using IBM SPSS version 1.0.0, a Chi-square test was conducted to show statistical significance between all identified variables.

\section{Results}

Hispanic children have the highest rate of obesity in the U.S compared to all other races. Children aged 2 - 4 years old from Alabama were more at risk for being overweight and obese compared to those from Delaware. Those between 48 - 59 months of age were more at risk than the other age groups. Confidence Intervals were also included to show significance.

As identified in Table 1 which shows the 2014 demographic characteristics of children with obesity in Alabama and Delaware, an analysis of 43,509 children from Alabama were classified as being either obese or overweight. Comparison done for the different age groups show that age plays a large role in childhood obesity with age group 48 to 59 months having a higher percentage of overweight (17.6\%) and obese (18.6\%) children when compared to other age groups ranging from 24 - 47 months. Gender was not a precursor for childhood obesity as identified by the ratio of obese males and females. The race was found to be a contributing factor to childhood obesity with $20.3 \%$ of Hispanic children being overweight, while $25.2 \%$ were obese, a much higher percentage when compared to other races, as identified in Figure 1. In total, 16.5 percent of children in Alabama were found to be overweight compared to 16.3 percent who were found to be obese.

In the state of Delaware, 7251 children were classified as being either obese or overweight. As identified in Figure 2, comparison done for the different age groups show that age plays a large role in childhood obesity with age group 48 to 59 months having a higher percentage of overweight (16.3\%) and obese (21.6\%) children when compared to other age groups ranging from 24 - 47 months. Gender was not a precursor for childhood obesity as identified by the ratio of obese males and females. The race was found to be a contributing factor to childhood obesity with $25.9 \%$ of Hispanic children being overweight, while $24.2 \%$ were obese, a much higher percentage when compared to other races. There was no identified data on American Indian/Alaska children who were obese or overweight. In total, 16.2 percent of children in Delaware were found to be overweight compared to 17.2 percent who were found to be obese.

To show statistical significance, a chi-square test was conducted to test which variable(s) was directly associated with childhood obesity. The variables tested were age, gender, and race. As shown in Table 2, chi (8.727) > df (5.99) proved that age was statistically significant and is directly associated with one's weight; chi $(0.03599)<\mathrm{df}(3.84)$ proved that gender was not statistically significant and 
Table 1. 2014 demographic characteristics of children with obesity in two U.S. states.

\begin{tabular}{|c|c|c|c|c|c|c|}
\hline STATES & Obese (\%) & Low CI & High CI & $\begin{array}{c}\text { Overweight } \\
(\%)\end{array}$ & Low CI & High CI \\
\hline \multicolumn{7}{|l|}{ ALABAMA $(n=43,509)$} \\
\hline \multicolumn{7}{|l|}{ Age (months) } \\
\hline $24->35$ & 14.2 & 13.7 & 14.7 & 16 & 15.5 & 16.6 \\
\hline $36->47$ & 17 & 16.4 & 17.6 & 16.3 & 15.7 & 16.9 \\
\hline $48->59$ & 18.6 & 17.8 & 19.3 & 17.6 & 16.9 & 8.3 \\
\hline \multicolumn{7}{|l|}{ Gender } \\
\hline Male & 15.5 & 15.1 & 16 & 16.6 & 16.1 & 17.1 \\
\hline Female & 17 & 16.5 & 17.5 & 16.5 & 16 & 17 \\
\hline \multicolumn{7}{|l|}{ Race } \\
\hline Asian/Pacific Islander & 7.3 & 4.3 & 10.3 & 11.5 & 7.8 & 15.2 \\
\hline American Indian/Alaska Native & 13.8 & 10.4 & 17.3 & 14.6 & 11.1 & 18.2 \\
\hline Non-Hispanic Black & 14 & 13.5 & 14.5 & 15 & 14.5 & 15.5 \\
\hline Non-Hispanic White & 15.1 & 14.6 & 15.6 & 16.6 & 16.1 & 17.2 \\
\hline Hispanic & 25.2 & 24.2 & 26.2 & 20.3 & 19.4 & 21.3 \\
\hline \multicolumn{7}{|l|}{ DELAWARE $(\mathrm{n}=7251)$} \\
\hline \multicolumn{7}{|l|}{ Age (months) } \\
\hline $24->35$ & 14.3 & 13.1 & 15.6 & 16.3 & 15 & 17.6 \\
\hline $36->47$ & 18.5 & 17.1 & 19.9 & 15.9 & 14.6 & 17.3 \\
\hline $48->59$ & 21.6 & 19.2 & 23.9 & 16.3 & 14.2 & 18.4 \\
\hline \multicolumn{7}{|l|}{ Gender } \\
\hline Male & 17.8 & 16.6 & 9 & 16.6 & 15.4 & 17.8 \\
\hline Female & 16.5 & 15.3 & 7.8 & 15.7 & 14.5 & 16.9 \\
\hline \multicolumn{7}{|l|}{ Race } \\
\hline Asian/Pacific Islander & 10 & 5 & 15 & 7.9 & 3.3 & 12.4 \\
\hline American Indian/Alaska Native & 0 & 0 & 0 & 0 & 0 & 0 \\
\hline Non-Hispanic Black & 12.9 & 11.7 & 14.2 & 14.6 & 13.3 & 15.9 \\
\hline Non-Hispanic White & 15.2 & 13.6 & 16.8 & 15.6 & 14 & 17.3 \\
\hline Hispanic & 24.2 & 22.5 & 25.9 & 18.9 & 17.3 & 20.5 \\
\hline
\end{tabular}

is not directly associated with one's weight; chi (143.204) > df (9.49) proved that race was statistically significant and is directly associated with one's weight.

\section{Discussion}

After comparison of data for both the states of Alabama and Delaware, the values show that being Hispanic is a strongly significant factor to being either overweight or obese when compared to other races. Hispanic children are more prone to being overweight/obese due to socioeconomic factors such as family 


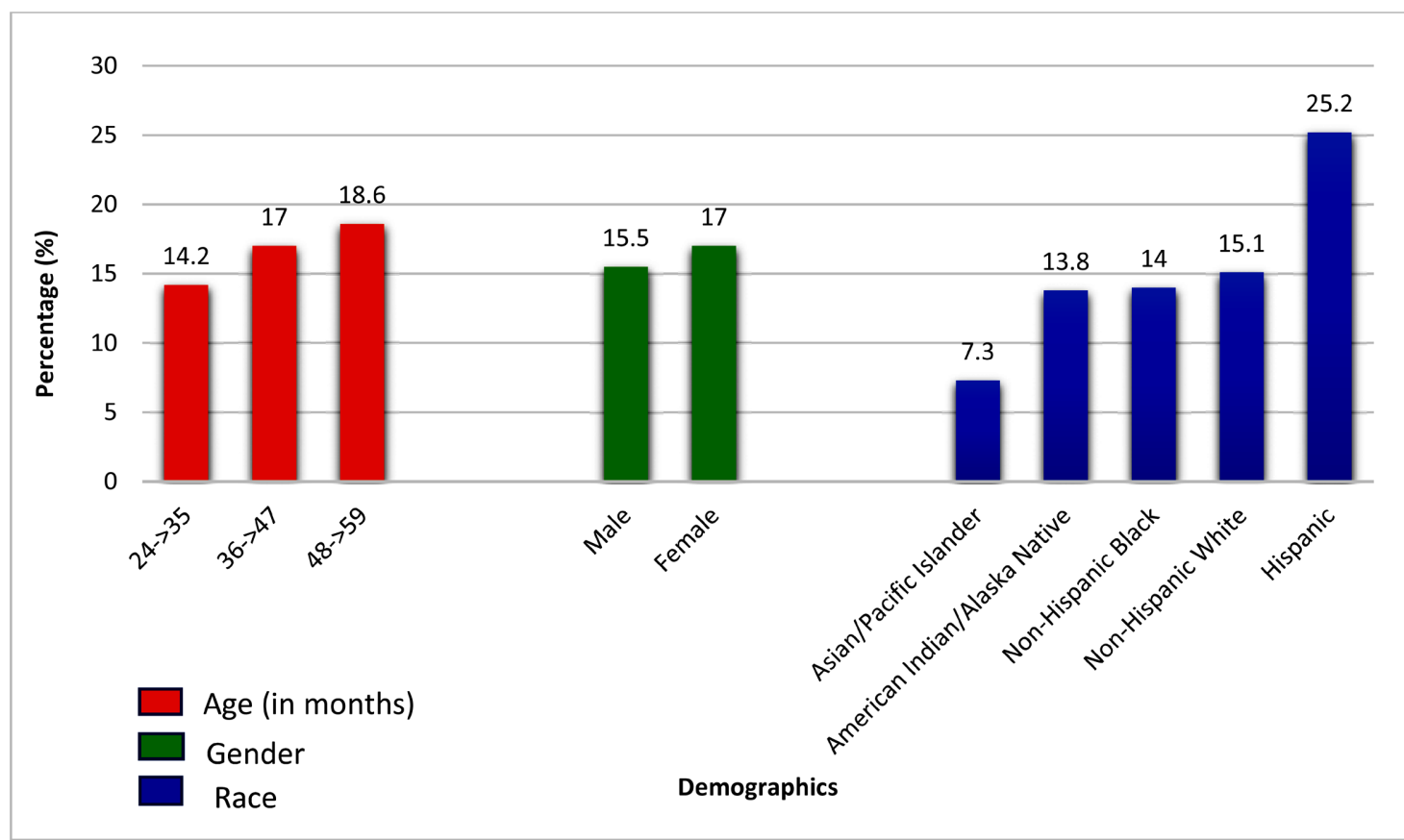

Figure 1. Demographic characteristics of childhood obesity in Alabama, 2014.

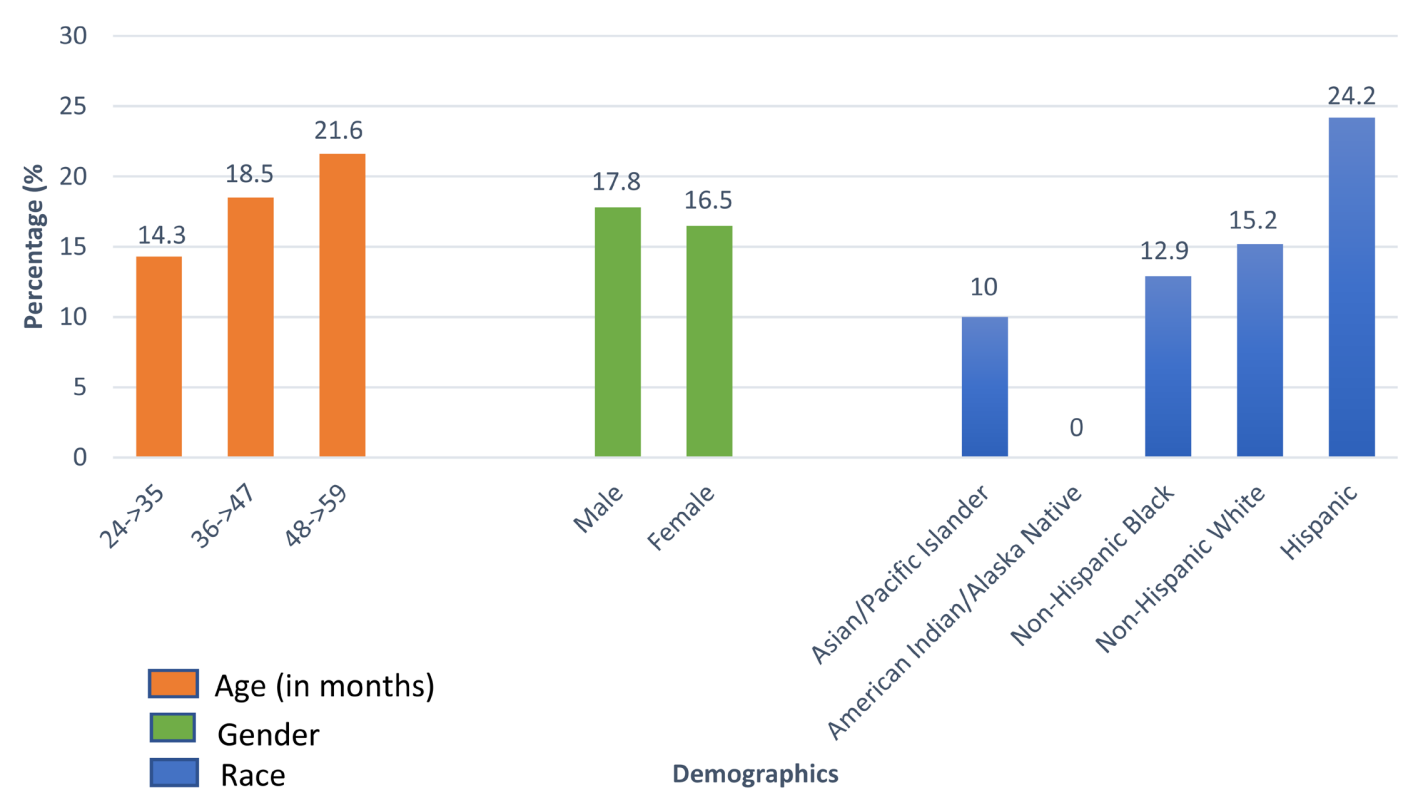

Figure 2. Demographic characteristics of childhood obesity in Delaware, 2014.

income level, educational level, geographical location, and immigration status. Additionally, the female populations are more predisposed to being overweight/obese when compared to the male population. Also, age is a factor because children who were between 48 months to 59 months showed more significance with a higher confidence interval than other age groups.

Some of the limitations to this study were missing data for some sample sizes/demographics, dataset irregularities/error (date appeared where age should), 
Table 2. Statistical analysis between variables for children with obesity in two U.S. states.

\begin{tabular}{|c|c|c|c|c|c|c|c|c|c|c|}
\hline \multicolumn{11}{|c|}{ CHI SQUARE TEST } \\
\hline & $\begin{array}{c}\text { Observed } \\
0\end{array}$ & $\begin{array}{c}\text { Observed } \\
\text { OV }\end{array}$ & $\begin{array}{l}\text { Row } \\
\text { Total }\end{array}$ & Expected & $\begin{array}{c}\text { Expected } \\
\text { OV }\end{array}$ & $\begin{array}{l}\text { Chi } \\
\text { Square } \\
\text { O }\end{array}$ & $\begin{array}{l}\text { Chi } \\
\text { Square } \\
\text { OV }\end{array}$ & Chi & df & Interpretation \\
\hline \multicolumn{11}{|l|}{ Age (months) } \\
\hline $24-35$ & 14.2 & 16 & 30.2 & 15.085 & 26.437 & 0.519 & 4.120 & 8.727 & $2=5.99$ & \multirow{4}{*}{$\begin{array}{c}\text { Reject Ho if chi square }>\text { df } \\
\text { Statistically Significant } \\
\text { Age is directly associated } \\
\text { with weight }\end{array}$} \\
\hline $36-47$ & 17 & 16.3 & 33.3 & 16.633 & 24.426 & 0.008 & 2.703 & & & \\
\hline $48-59$ & 18.6 & 17.6 & 36.2 & 18.082 & 24.261 & 0.015 & 1.829 & & & \\
\hline Column Total & 49.8 & 49.9 & 99.7 & & & & & & & \\
\hline \multicolumn{11}{|l|}{ Gender } \\
\hline Male & 15.5 & 16.6 & 32.1 & 15.693 & 17.117 & 0.002 & 0.016 & 0.036 & $1=3.84$ & \multirow{4}{*}{$\begin{array}{l}\text { Do not reject Ho chi }<\text { df } \\
\text { Not Statistically Significant } \\
\text { Gender is not directly } \\
\text { associated with weight }\end{array}$} \\
\hline Female & 17 & 16.5 & 33.5 & 16.493 & 16.303 & 0.016 & 0.002 & & & \\
\hline Column Total & 32.5 & 33.1 & 65.6 & & & & & & & \\
\hline \multicolumn{10}{|l|}{ Race } & \\
\hline Asian/Pacific Islander & 7.3 & 11.5 & 18.8 & 29.278 & 47.713 & 16.498 & 27.485 & 143.204 & $4=9.49$ & \multirow{6}{*}{$\begin{array}{c}\text { Reject Ho because chi square }> \\
\text { df } \\
\text { Statistically Significant } \\
\text { Race is directly associated } \\
\text { with weight }\end{array}$} \\
\hline $\begin{array}{l}\text { American Indian/ } \\
\text { Alaska Native }\end{array}$ & 13.8 & 14.6 & 28.4 & 36.638 & 40.099 & 14.236 & 16.214 & & & \\
\hline Non-Hispanic Black & 14 & 15 & 29 & 36.4 & 40.345 & 13.785 & 15.922 & & & \\
\hline Non-Hispanic White & 15.1 & 16.6 & 31.7 & 35.916 & 40.845 & 12.064 & 14.392 & & & \\
\hline Hispanic & 25.2 & 20.3 & 45.5 & 41.76 & 34.8 & 6.567 & 6.042 & & & \\
\hline Column Total & 75.4 & 78 & 153.4 & & & & & & & \\
\hline
\end{tabular}

not enough risk factors represented, delay between data collection and reporting (the most recent published obesity rates from the NHANES are from 20132014). There was a lack of adequate data set to compare other risk factors associated with obesity in the Hispanic population.

The strengths of this study are that it included all the races of children in the United States. It examined a nationally representative sample of Americans ages 2 and older. It included a large sample size of children aged 3 months to 59 months from different races for six continuous years. It combines interviews with physical examinations, increasing the accuracy of the data.

Including other risk factors such as parent's educational level, immigrant generation, and household language would have further strengthened the study. Another limitation was the missing data for American Indians in the state of Delaware. Having a completion date for all races would have helped with a better comparison between the two (2) U.S. states.

\section{Conclusions}

In conclusion, being overweight is considered a risk factor for childhood obesity which could, in turn, lead to adult obesity later in life if contributing factors are not identified early enough. With the race being one of the predisposing factors, 
one's culture does indeed influence the type of food eaten and portion size. Other identifying factors such as parental influence, genetics, and method of transportable also play a major role in a child's diet. This is because parents of children from a poor background might be too busy working and not have the luxury of time and money to buy or cook healthy foods often settling with just the fast-food option which is not as healthy. Genetics plays a major role in the weight of a child with several identified cases of children with parents/family members who were obese, hence, having a higher tendency of being overweight or obese themselves. Additionally, lack of transportation could negatively affect their food choices. It is certainly an issue because it limits the parent from easily accessing a grocery store; it also limits their access to educational nutritional programs [8].

\section{What is already known on this topic}

- Previous research shows that overweight kindergartners had four times the risk of becoming obese by the age of 14 years as normal-weight kindergartners [9].

- Another study revealed that breastfeeding was a protective factor against obesity, especially when given at the early stages of one's life.

\section{What this study adds}

- This study analyses predisposing factors such as age, gender, and race that contribute to childhood obesity.

- This study indicates that breastfeeding at 1 year of age was associated with a decreased weight percentile for age, body mass index percentile and z-score for age, and waist circumference below the 90th percentile [10].

\section{Conflicts of Interest}

The author declares no conflicts of interest regarding the publication of this paper.

\section{References}

[1] Jun-Hyun, K., Chanam, L., Olvera, N. and Ellis, C. (2014) The Role of Landscape Spatial Patterns on Obesity in Hispanic Children Residing in Inner-City Neighborhoods. Journal of Physical Activity and Health, 11, 1449-1457. https://doi.org/10.1123/jpah.2012-0503

[2] Mejia de Grubb, M.C., Salemi, J.L., Kihlberg, C., Gonzalez, S., Zoorob, R. and Levine, R. (2017) Disparities in Accuracy of Maternal Perceptions of Obesity among Hispanic Children. Journal of Health Care for the Poor and Underserved, 28, 1208-1221. https://doi.org/10.1353/hpu.2017.0106

[3] Centers for Disease Control and Prevention (2007) Overweight and Obesity. Centers for Disease Control and Prevention. https://www.cdc.gov/obesity/childhood/defining.html, Accessed March 14, 2018.

[4] Sahoo, K., Sahoo, B., Choudhury, A.K., Sofi, N.Y., Kumar, R. and Bhadoria, A.S. (2015) Childhood Obesity: Causes and Consequences. Journal of Family Medicine and Primary Care, 4, 187-192.

[5] Iriart, C., Boursaw, B., Rodrigues, G.P. and Handal, A.J. (2013) Obesity and Malnu- 
trition among Hispanic Children in the United States: Double Burden on Health Inequities. Revista Panamericana de Salud Publica, 34, 235-243.

[6] Knowlden, A.P. and Sharma, M. (2013) Systematic Review of School-Based Obesity Interventions Targeting African American and Hispanic children. Journal of Health Care for the Poor and Underserved, 24, 1194-1214.

https://doi.org/10.1353/hpu.2013.0129

[7] Data.gov Catalog (2018) Nutrition, Physical Activity, and Obesity-Women, Infant, and Child.

https://catalog.data.gov/dataset/nutrition-physical-activity-and-obesity-women-infa nt-and-child, April 2018, Accessed 2 May 2018.

[8] Arauz Boudreau, A.D., Kurowski, D.S., Gonzalez, W.I., Dimond, M.A. and Oreskovic, N.M. (2013) Latino Families, Primary Care, and Childhood Obesity: A Randomized Controlled Trial. American Journal of Preventive Medicine, 44, S247-S257.

https://doi.org/10.1016/j.amepre.2012.11.026

[9] Cunningham, S.A., Kramer, M.R. and Narayan, K.V. (2014) Incidence of Childhood Obesity in the United States. The New England Journal of Medicine, 370, 403-411. https://doi.org/10.1056/NEJMoa1309753

[10] Verstraete, S.G., Heyman, M.B. and Wojcicki, J.M. (2014) Breastfeeding Offers Protection against Obesity in Children of Recently Immigrated Latina Women. Journal of Community Health, 39, 480-486. https://doi.org/10.1007/s10900-013-9781-y 


\section{Annex. STROBE Statement-Checklist of Items}

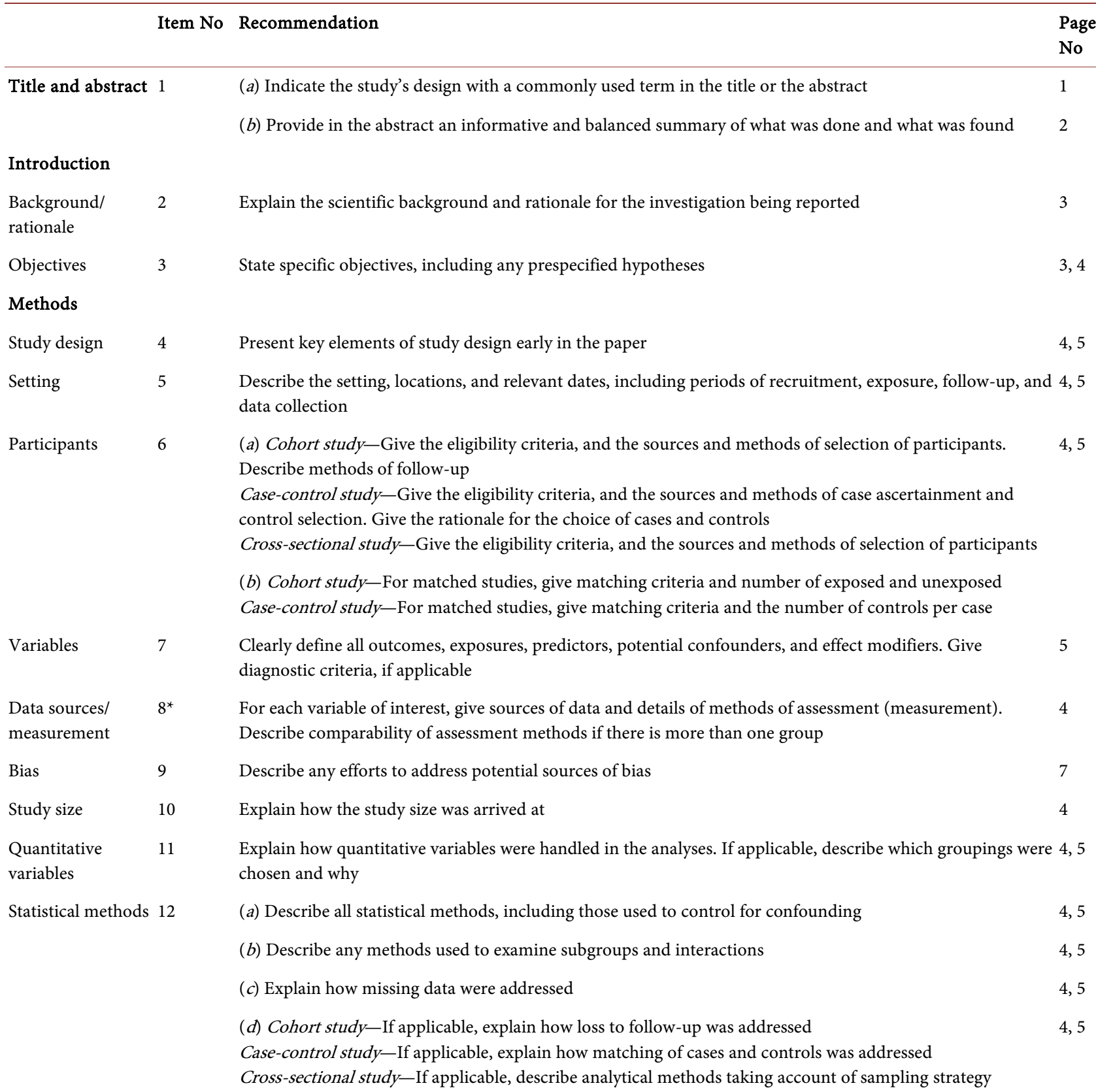

(e) Describe any sensitivity analyses

\section{Results}

Participants $\quad 13^{*} \quad$ (a) Report numbers of individuals at each stage of study-e.g. numbers potentially eligible, examined for 5, 6 eligibility, confirmed eligible, included in the study, completing follow-up, and analyzed

$\begin{array}{ll}\text { (b) Give reasons for non-participation at each stage } & 5,6\end{array}$

$\begin{array}{ll}\text { (c) Consider use of a flow diagram } & 5,6\end{array}$

Descriptive data $14^{\star} \quad$ (a) Give characteristics of study participants (e.g. demographic, clinical, social) and information on 5,6 exposures and potential confounders

(b) Indicate number of participants with missing data for each variable of interest 


\section{Continued}

(c) Cohort study-Summarize follow-up time (e.g., average and total amount)

Outcome data

Case-control study-Report numbers in each exposure category, or summary measures of exposure

Cross-sectional study-Report numbers of outcome events or summary measures

Main results

Other analyses

Discussion

Key results

Limitations

Interpretation

Generalizability

Other information

Funding

(a) Give unadjusted estimates and, if applicable, confounder-adjusted estimates and their precision (e.g., 95\% 5, 6 confidence interval). Make clear which confounders were adjusted for and why they were included

(b) Report category boundaries when continuous variables were categorized

(c) If relevant, consider translating estimates of relative risk into absolute risk for a meaningful time period

Report other analyses done-e.g. analyses of subgroups and interactions, and sensitivity analyses

Discuss limitations of the study, taking into account sources of potential bias or imprecision. Discuss both 7 direction and magnitude of any potential bias

Give a cautious overall interpretation of results considering objectives, limitations, multiplicity of analyses, 6,7 results from similar studies, and other relevant evidence

Discuss the generalizability (external validity) of the study results

Give the source of funding and the role of the funders for the present study and, if applicable, for the original 1,7 study on which the present article is based 